\title{
Human Infections with Staphylococcus aureus CC398
}

\author{
Tara C. Smith • Shylo E. Wardyn
}

Published online: 8 January 2015

(C) Springer International Publishing AG 2015

\begin{abstract}
Staphylococcus aureus isolates belonging to clonal cluster 398 (CC398) have emerged over the previous decade as a risk to livestock workers. Though most of the research to date has focused on colonization with these strains, a number of infections have also been documented, ranging from mild skin infections to more serious invasive infections and even death. Here, we review existing reports of human infections with CC398 and discuss their geographic distribution, general characteristics, and implications for future research. We identified 74 publications describing CC398 infections in humans in 19 different countries, suggesting this is an emerging worldwide issue.
\end{abstract}

Keywords MRSA $\cdot$ Staphylococcus aureus $\cdot$ Zoonotic disease $\cdot$ Livestock $\cdot$ Antibiotic resistance $\cdot$ Staph infections

\section{Introduction}

Staphylococcus aureus is a leading cause of infectious disease morbidity throughout the world [1]. The bacterium is particularly problematic in hospitals, where it can complicate surgeries and spread nosocomially [2]. Infections often develop in open wounds or medical devices, such as catheters, and can

This article is part of the Topical Collection on Food, Health, and the Environment

T. C. Smith $(\bowtie)$

Kent State University College of Public Health, 750 Hilltop Drive, Lowry Hall, Kent, OH, USA

e-mail: tsmit176@kent.edu

Present Address

S. E. Wardyn

Fred Hutchinson Cancer Research Center, Seattle, WA, USA

swardyn@fhcrc.org also cause more serious conditions, including ventilatorassociated pneumonia [3] and bacteremia [4].

In the past 20 years, two new groups of methicillinresistant S.aureus (MRSA) have emerged. Previously, MRSA was primarily observed in hospital settings (hospital-acquired MRSA [HA-MRSA]). In the 1990s, novel strains of MRSA found in individuals with no healthcare contact were termed "community-associated MRSA" (CAMRSA) [5]. These isolates tend to carry an SCCmec cassette smaller than that typically found in HA-MRSA and are resistant to fewer classes of antibiotics. CA-MRSA also tends to carry a putative virulence gene, the Panton-Valentine leukocidin gene (PVL) [6]. A decade later, a third type of MRSA was identified, typically among individuals working with livestock (livestock-associated MRSA [LAMRSA]) [7, 8]. LA-MRSA has unique characteristics that distinguish it from HA-MRSA and CA-MRSA. LA-MRSA isolates typically are multilocus sequence type (MLST) 398 (ST398), belonging to clonal cluster 398 (CC398), and are resistant to digestion with the enzyme $\mathrm{SmaI}$ in pulsed field gel electrophoresis (PFGE) analysis [9]. Multiple reports have shown that they also typically lack common toxin genes frequently carried by human S.aureus isolates [10-12].

The majority of publications examining LA-MRSA to date have focused on colonization in both animals (typically, swine, cattle, poultry, and horses) and their human caretakers or veterinarians [13-17]. However, an increasing number of case reports and hospital-based research have identified CC398 as a cause of symptomatic infections. Furthermore, in the past 3 years, CC398 has been split into two distinct lineages: those that are of human origin $[18,19 \cdot, 20]$ and those that are truly livestock adapted. Human-origin CC398 isolates tend to be susceptible to tetracycline and methicillin, and carry the scn gene. In this review, we discuss reported cases of CC398 clinical infections in humans, as well as the 
implications of the emergence of this strain in livestock and in humans. Reports were collected via review in PubMed, Medline, and Embase, searching for "ST398," "CC398," "livestock-associated MRSA," and "livestockassociated Staphylococcus aureus" as of July 2014. Additional publications were also found via reference sections of collected manuscripts. Papers were included if they documented infections due to isolates identified either as ST/CC398 or spa types that are typically associated with this clonal complex (including t011, t034, t571, and others, as documented in Table 1). Information on human versus livestock-adapted cases is provided when known.

\section{Geographic Distribution of Cases}

To date, the majority of CC398 clinical infections have been reported in Europe, where most research on CC398 has been focused, and many countries have established surveillance programs for S.aureus infections (see Table 1). Seventy-four publications were identified. Human infections of any type have been reported in Austria [21-24], Belgium [23, 25, 26], Denmark [23, 27-31], Finland [23, 32], France [33-35, 36•, 37-39], Germany [23, 40-44], Greece [45], Italy [46-51], the Netherlands [23, 52-63], Norway [64], Spain [65-71], Sweden [72, 23], Scotland [73], and Switzerland [23]. Outside of Europe, infections have been described in Canada [74], China

Table 1 Summary of CC398-associated infections reported in the literature

\begin{tabular}{|c|c|c|c|c|}
\hline CC398-associated spa types & SCCmec types & PVL & Countries & References \\
\hline $\mathrm{t} 011, \mathrm{t} 034, \mathrm{t} 190, \mathrm{t} 1451$ & $\mathrm{~V}, \mathrm{NR}$ & Neg & Austria & {$[21,22,24,100]$} \\
\hline $\mathrm{t} 011, \mathrm{t} 571$ & $\mathrm{~V}, \mathrm{NR}, \mathrm{N} / \mathrm{A}$ & Neg & Belgium & {$[25,26,102]$} \\
\hline $\mathrm{t} 034, \mathrm{t} 1250$ & $\mathrm{~V}$ & Neg & Canada & [74] \\
\hline $\begin{array}{l}\mathrm{t} 011, \mathrm{t} 034, \mathrm{t} 571, \mathrm{t} 588, \mathrm{t} 1250, \mathrm{t} 1255, \mathrm{t} 1451 \\
\text { t3625, t4387, ND }\end{array}$ & III, IV, N/A & Pos and Neg, NR & China & {$[75-80]$} \\
\hline 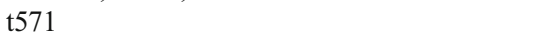 & N/A & Neg & Colombia & [81] \\
\hline $\mathrm{t} 034, \mathrm{t} 108, \mathrm{t} 1793$ & IV, V, NT, NR & Pos and Neg, NR & Denmark & {$[11,27-31,133]$} \\
\hline $\mathrm{t} 571, \mathrm{t} 3625$ & N/A & NR & Dominican Republic & [82] \\
\hline t011, t034 & IV, V & Pos and Neg & Finland & {$[32]$} \\
\hline $\begin{array}{l}\text { t011, t034, t108, t571, t588, t614, t899, t937, } \\
\text { t1149,t1184, t1250, t1451, t2155, t2370, } \\
\text { t3085, t3642, t4293, t4615, t4896, t5635, } \\
\text { t5719, t5881, t6604, t6605, t6606, t6608, } \\
\text { t8587, t8592,t8593, t9378, NR }\end{array}$ & IV, V, N/A, NR & Pos and Neg, NR & France & {$[33,34,37-39,134]$} \\
\hline $\begin{array}{l}\mathrm{t} 011, \mathrm{t} 034, \mathrm{t} 108, \mathrm{t} 567, \mathrm{t} 571, \mathrm{t} 899, \mathrm{t} 1250 \\
\mathrm{t} 1255, \mathrm{t} 1451, \mathrm{t} 1580, \mathrm{t} 2011, \mathrm{t} 2330 \\
\mathrm{t} 2346, \mathrm{t} 2510, \mathrm{t} 2576, \mathrm{t} 2970\end{array}$ & IV, V, NR & Neg & Germany & {$[40-44]$} \\
\hline NR & NR & NR & Greece & {$[45]$} \\
\hline t011, t034, t2346, NR & IVa, N/A & Pos and Neg, NR & Hong Kong & {$[85,84]$} \\
\hline t899, NR & $\mathrm{IVa}$ & Neg & Italy & {$[46-49,51]$} \\
\hline $\begin{array}{l}\text { t011, t034, t108, t567, t571, t898, t899, } \\
\text { t943, t1254, t1255, t1451, t1939, t2011, } \\
\text { t2123, t2383 }\end{array}$ & IV, IVa, V*, NR, N/A & Neg, NR & The Netherlands & $\begin{array}{l}{[14,15,41,52,53,57} \\
\quad 59-63,99,101 \\
\quad 103,135]\end{array}$ \\
\hline t034 & $\mathrm{V}$ & Pos & Norway & {$[64]$} \\
\hline t034 & III & NR & Scotland & [73] \\
\hline $\mathrm{t} 011, \mathrm{t} 108, \mathrm{t} 899, \mathrm{t} 1197, \mathrm{t} 1255, \mathrm{t} 1451$ & IV, IVa, V & Neg & Spain & {$[66-71]$} \\
\hline t034 & NR & Pos & Sweden & {$[72]$} \\
\hline \multirow[t]{2}{*}{ t034, t571, t1451, NR } & N/A & Neg & USA & {$[12,19 \bullet, 86-88]$} \\
\hline & N/A & Neg & Dominican Republic, Martinique & [83] \\
\hline $\mathrm{t} 571, \mathrm{t} 1451, \mathrm{t} 5635$ & NR & Pos and Neg & $\begin{array}{l}\text { Canada, Dominican Republic, } \\
\text { Martinique, the Netherlands, } \\
\text { USA }\end{array}$ & {$[18]$} \\
\hline $\begin{array}{l}\text { t011, t034, t108, t567, t571, t588, t753, t898, } \\
\text { t899, t1184, t1254, t1255, t1451, t1456, } \\
\text { t1457, t2123, t2330, t2383, t2582, t3013 }\end{array}$ & NR & NR & $\begin{array}{l}\text { Austria, Belgium, Denmark, } \\
\text { Finland, Germany, Italy, } \\
\text { the Netherlands, Sweden }\end{array}$ & {$[23]$} \\
\hline
\end{tabular}

MSSA methicillin-susceptible Staphylococcus aureus, N/A not applicable (MSSA), Neg negative, NR not reported, NT nontypeable, $N D$ not determined, Pos positive, $P V L$ Panton-Valentine leukocidin gene

*Several type III isolates typed using a previous method [136] were subsequently found to be type V [137] 
[75-80], Colombia [81], the Dominican Republic [82, 83], Hong Kong [84, 85], Martinique [83], and the USA [12, 18, 19•, 86-88].

Though nationwide data are still lacking in many countries, a large study examined data from 24 laboratories in 17 European countries [23]. On the basis of data from 2007, ST398 was detected in $8 / 15$ countries for which typing data were available. Of the 8,262 MRSA isolates typed for this study, $142(1.7 \%)$ were ST398. The percentages of ST398associated types were highest in the Netherlands $(11.7 \%)$, Belgium (4.7\%), Denmark (1.6\%), and Austria (1.4\%). The proportion of ST398 isolates was found to correlate with the density of pig herds, as well as with cattle density to a lesser extent. These numbers likely underestimate the prevalence of ST398 infections, as only previously identified spa types associated with ST398 were included. Additional unidentified types may also exist.

In the Netherlands, a recent dramatic increase in the prevalence of CC398 in recovered MRSA isolates has been observed, changing from $0 \%$ in 2002 to $30 \%$ in 2007 following increased surveillance instituted in 2006 [52, 53, 56, 60]. Interestingly, one publication found two isolates of methicillin-susceptible S. aureus (MSSA) ST398 in the Netherlands in a retrospective survey dating back to 1997 [57]. These isolates were identified in a collection of S.aureus isolates taken from intensive care unit patients from 14 hospitals in the country. Both ST398 isolates identified were from the southern region of the country, which is an agricultural region. Whether these dramatic increases will occur in other countries where CC398 has been found remains to be seen, particularly as surveillance for these organisms varies widely from country to country.

In China, a large study that examined isolates collected from 1994 to 2008 in a Chinese tertiary hospital determined that the CC398-associated spa type 1571 was one of the most common MSSA types $(18 / 164 ; 11 \%$ of all MSSA during the period) [76]. The related spa types t034 and t1250 were also present at lower levels, while, overall, CC398 was the most common type of MSSA (31/164; $18.9 \%$ of all isolates). All isolates came from sterile body sites. The high levels of CC398-associated spa types observed is interesting, as most MRSA from Chinese pigs has been ST9, not ST398 [89-91], though one recent paper did describe ST398 in Chinese pigs [92]. Thus, most CC398-associated types in China may be of human rather than livestock origin [93].

To date, five reports containing documentation of human symptomatic infections with CC398 have been published in the USA $[12,18,19 \bullet, 86,87]$. None have been found to be MRSA, despite confirmation of MRSA CC398 in pigs and pig workers in this country [17, 94-97]. This discrepancy may be due in part to a lack of systematic nationwide surveillance in the USA, particularly in rural areas, where livestockassociated strains are most likely to be found. The isolates described in all reports originated in urban locations, from the New York metropolitan area $[12,18,19 \bullet, 86]$ and St.Louis, Missouri [87]. In the St.Louis report, one PVL-negative ST398 isolate was identified from a wound/abscess [87], and one blood isolate of ST398 MSSA was identified from the Bronx report [12]. This isolate was PVL negative but did carry the ser gene, which encodes an enterotoxin of unknown function.

Additionally, self-reported infections in US swine workers have been documented [98]. Five of 135 participants (3.7\%) reported a history of physician-diagnosed MRSA skin and soft tissue infection (SSTI). The only significant variable found to be a risk factor in the bivariate model for this population was having employees who expressed concern regarding MRSA $(p=0.02)$, but in a multivariate model, no risk factors were found to be significant. This publication used retrospective questionnaire data, so it cannot be determined whether all of the reported MRSA infections were indeed culture-positive MRSA, and, if so, whether these infections were due to CC398 or other strains. Another limitation was that the National Pork Board producer database used to recruit participants for the study consisted mainly of smaller owneroperators, while many employees of such individuals were not evaluated directly.

\section{Types of Infections}

A spectrum of CC398 infections has been documented, ranging from relatively minor or localized infections (including abscesses [46, 62, 64, 72, 87, 99, 100] and various SSTIs [11, $18,21,30,31,37,48,53,60,66,69,74,77,79,80,85,101]$; urinary tract infections $[60,62]$; wound infections $[21,26,32$, 40, 59-62, 72, 75, 86, 100, 102]; mastitis [15]; otitis [51, 60]; tonsillitis [31], and conjunctivitis [22]) to more serious or invasive infections (including bacteremia [12, 24, 26, 28, 33, $34,37,43,45,48,60,62,63,81,84,86]$; pneumonia, including necrotizing pneumonia $[21,26,30,37,40,47,53$, 78]; osteomyelitis [22, 39, 53]; pyomyositis [46]; otomastoiditis [25]; endocarditis [38, 103]; multi-organ failure [27], and postoperative infections [21]). Although most of these cases have been documented in the past 5 years, one MSSA ST398 bacteremia isolate from Denmark dates back to 1992 [28].

Despite the diverse array of infection types, it has been suggested that CC398 isolates may not cause as much disease (relative to colonization) as other human strains, such as USA300 [53, 104]. Supporting this assertion, a targeted study examining invasive S.aureus isolates in Europe found that ST398 was responsible for only $0.4 \%$ of those infections, and none were methicillin resistant [105]. Van Cleef et al. also found that in their surveillance, the proportion of ST398 isolates from blood was significantly lower than for other 
MRSA types, suggesting a less invasive phenotype [23]. However, some disease manifestations may be enriched for CC398 strains. A French study of osteomyelitis complicating diabetic foot ulcers demonstrated that MSSA CC398 was the dominant clone in these infections, accounting for $38 \%$ of cases of diabetic foot osteomyelitis and appearing in 10 of the 12 clinics monitored [39]. These isolates were found to carry molecular signatures of human, rather than livestock, adaptation.

While many early studies have focused on skin and wound infections, this approach may miss some CC398 infections, as one study has suggested that $\mathrm{CC} 398$ was more likely to be associated with respiratory disease rather than skin infections [52]. Another study [60] reported three sputum ST398 isolates but no SSTI among 30 isolates, although there were also 10 wound infections and 4 diabetic foot infections reported. However, these findings were not replicated in a larger study, which found no significant difference between ST398 MRSA and other MRSA types in regard to respiratory infections [23]. Conversely, Lewis et al. reported that all patients who developed symptomatic infections with ST398 were SSTIs, with one later developing sinusitis and another developing multiorgan failure [27].

\section{Respiratory Infections}

As noted above, there is conflicting evidence regarding the preponderance of $\mathrm{CC} 398$ in respiratory infections versus SSTI. While the prevalence of CC 398 as a cause of respiratory infections remains unclear, there have been several case reports documenting ST398 respiratory infections. A 2011 report found ST398-associated pneumonia in a Chinese girl. This isolate was negative for most toxins tested but positive for exfoliative toxin (eta) [78]. A Dutch paper noted one case of pneumonia from three identified ST398 infections [53]. Several publications have reported ST398 isolates from bronchial aspirate or lavage specimens [21, 47]. Others have described ST398 pneumonia in individuals associated with pig farming [30] or in those for whom contact with livestock could not be determined [26].

\section{CC398 Fatalities}

Despite the reputation of CC398 as a more "mild" type of $S$. aureus, there have been several reported deaths due to $\mathrm{CC} 398$ infections. Lozano et al. described a fatal infection in a 79year-old patient in Spain [68]. The patient was hospitalized, and MRSA was isolated from a thoracic drainage tube and tracheal aspirate, as well as from a nasal swab. The isolates were typed and found to be spa type t011 and SCCmec type V, both molecular types frequently associated with ST398 strains. Though the patient was treated with intravenous levofloxacin (later changed to linezolid), treatment was unsuccessful, and the patient died following multi-organ failure. The patient lived with his wife and two sons on a pig farm; cultures from swine and one son were found to be identical to the patient's samples. Both sons worked on the farm, and the patient worked there sporadically, suggesting acquisition from swine, with possible intrafamilial transmission.

Four CC398 deaths have been reported in France in three publications. In the first report, Van der Mee-Marquet et al. analyzed annual surveys of bloodstream infections performed in the central region of France [34]. In 2009, the emergence of cases associated with tetracycline-sensitive, PVL-negative, spa type t571 strains was noted. One individual had a history of exposure to animals - a fatal idiopathic communityassociated bloodstream infection in an 84-year-old man, who lived on a farm with one pig. The other cases were hospitalacquired bloodstream infections in a 58-year-old man with multiple myeloma, and two cases following surgeries: one an elective digestive tract surgery in a 69-year-old woman, and another after cardiac surgery in a 68-year-old man.

In the second French publication, a previously healthy 14year-old girl was seen at the emergency room with a flu-like illness, cough, fever, and a 2-day history of severe abdominal pain [35]. She was given intravenous antibiotics (cefotaxime and amikacin), and an exploratory laparotomy was performed. Immediately after surgery, the girl went into acute respiratory distress, and mechanical ventilation was required. S.aureus was isolated from bronchoalveolar lavage fluid and a blood culture, and the girl was diagnosed with necrotizing pneumonia. The patient died 6 days after symptom onset, and the origin of the infection was not determined. In this instance, the spa type was t571 and the isolate was sensitive to methicillin and tetracycline, similar to the other cases reported in that country [34, 37, 39] and elsewhere [76]. This isolate was also PVL positive. Two additional deaths were reported in a third paper [33], in a 59-year-old male and an 80-year-old male. Both deaths were caused by MSSA t571 strains.

One CC398-associated death has also been reported in China, in a 3-year-old who underwent empyema surgery and had an abscess [75]. The spa type of this isolate was not provided, but the isolate was SCCmec type IV and resistant to penicillin, erythromycin, and gentamicin, but susceptible to tetracycline. This death was not reported in the original study but was referenced in a later publication [79].

\section{Predisposing Conditions}

As is common with clinical infections with $S$.aureus, a number of individuals described in case reports had various predisposing conditions. Previous studies have shown that individuals with immunocompromising conditions (including 
diabetes) are at higher risk of infections [106], as are individuals aged 65 years and older [107]. Diabetes was described in a number of publications detailing CC398 infections [25, 39, $47,49,59,60,70,81]$, while individuals of advanced age were noted in others [21, 22, 26, 32, 34, 47, 68, 70, 74, 75]. Additional conditions noted included congenital arteriovenous malformations [49], history of renal transplantation/ immunosuppressive drugs [79, 103], obesity [48], young age $[22,30,52]$, cancer [34, 45, 68], and skin conditions [99], as well as one case of infection in a 16-year-old girl with muscular atrophy type II, which left her in a wheelchair and on artificial ventilation [61]. A recent graft infection was also noted in Colombia in a woman who had a medical history including diabetes mellitus, hypertension, valvular heart disease, and chronic arterial occlusive disease [81].

\section{Lack of Animal Contact and Human-Origin CC398 Strains}

Though most instances of both CC398 colonization and infection have been in individuals who have occupational contact with live animals (particularly swine and cattle), a number of reports have documented CC398 infections in individuals lacking any confirmed animal contact. Many studies for which animal contact is unknown result from an inability to obtain such information, due to the study design (such as the use of retrospective hospital records without any patient follow-up) [19•, 26, 33, 37, 74, 86, 87]. In other instances, despite other available information or follow-up interviews with infected patients, still no animal contact was uncovered [32, 45, 47, 49, $60,72,99]$. In one of the largest studies of CC398 infections, $11 / 30$ patients $(36.7 \%)$ had no known contact with livestock [60].

A human reservoir for some t571 CC398 strains has also been suggested [93], eliminating the need for any animal reservoir. There is growing evidence to support this hypothesis. A recent study examining CC398 infections in New York and New Jersey found 13 samples of ST398 and ST291 (a single-locus variant of ST398) from 2004 to 2010; of the ST398 isolates, 6/8 samples were t571. Indeed, in European studies, t571 is uncommon in pigs, accounting for only a single ST398 sample found during sampling of breeding pigs in the European Union [108]. Some t571 and t1451 strains do show unique properties that are not typical of swineassociated lineages $[33,38,82]$. Most are sensitive to methicillin and tetracycline. Van der Mee-Marquet additionally described interesting lineages that appeared to have properties of common ST398 strains, the community-associated strain USA300, and Chinese ST398 isolates, suggesting the potential for horizontal transmission of virulence genes into ST398 lineages [34, 53]. Investigation of an MSSA ST398 t571 infection in a Colombian woman found no evidence of livestock contact, although she did live in a rural area and had contact with chickens, which may also carry CC398 strains $[109,110]$. This isolate, while sensitive to methicillin, was resistant to tetracycline - a hallmark of livestockassociated strains [81].

A genomic analysis of 89 strains further suggests that ST398 does have a "human" lineage. This lineage appears to have originated as MSSA, which was transmitted to farm animals, subsequently acquired resistance to methicillin and tetracycline via agricultural antibiotic use, and is now being transmitted to human caretakers [19•]. This evolutionary course is reminiscent of the situation in the poultry population, where an ST5 lineage was introduced into commercial poultry flocks by humans, where it subsequently evolved antibiotic resistance and has been transmitted back to humans on occasion [111]. As previously suggested, t571 spa types have been more strongly correlated with human infections (as opposed to animal colonization strains), and the majority of those tested have been MSSA, tetracycline sensitive, and positive for the $\varphi \mathrm{Sa} 3$ prophage, suggesting adaptation to humans. In all but one of the animal-origin ST398 isolates tested in this study, $\varphi \mathrm{Sa} 3$ was lost. A second paper examining human-origin MSSA ST398 strains and a livestock-origin MRSA ST398 isolate reported similar findings, along with evidence that the apparently human-origin strains also demonstrated increased adherence to human epidermal keratinocytes, compared with LA-MRSA strains, suggesting additional host adaptations [18]. A third paper demonstrated heterogeneity amongst isolates in a variety of responses to in vitro assays, suggesting the existence of a hypervirulent lineage within ST398 [112]. However, in this study, all isolates tested were 011 or t034, rather than $\mathrm{t} 571$. As such, it is possible for these spa types to also show the potential for increased virulence. A recent French paper examining 189 CC398 isolates taken from patients with S.aureus infections and from pigs and cattle colonized with S.aureus determined that a multiplex PCR targeting the scn, chp, and erm T genes could discriminate animal and human origin CC398 isolates [37], while another recent paper examined the presence of $s c n$ and tet( $(\mathrm{M})$ along with a single nucleotide polymorphism (canSNP) assay as a method to distinguish animal and human origin isolates [113].

\section{Conclusions and Future Studies and Unanswered Questions}

A decade since the initial recognition of ST398, there still exist a number of unanswered questions regarding the epidemiology and clinical relevance of this strain. CC398 strains have been suggested by several studies to be less transmissible between humans than non-CC398 types in several European studies $[114,115]$. One study in the Netherlands quantified this difference, estimating that ST398 was $72 \%$ less 
transmissible than other strains in Dutch hospitals [115]. More recently, in the Netherlands, transmissibility of LA-MRSA was found to be 4.4 times lower than that of MRSA not associated with livestock [116]. The duration of carriage of this strain following exposure is also uncertain, with several studies suggesting carriage is quickly lost $[95,117]$ and others suggesting a longer duration of colonization $[118,119]$. These studies have examined livestock-adapted CC398 types for the most part. Studies are still lacking to quantify the transmission potential and carriage duration of human types of CC398 strains. As these strains have no clear reservoir, such studies may be more difficult to carry out epidemiologically. Artificial inoculation studies have also been conducted using livestockadapted strains, finding that they do successfully compete with other "human" strains of S. aureus [120]. Thus, CC398 isolates, even livestock-adapted ones, do seem to have the ability to effectively colonize hosts and cause symptomatic infections.

It should be noted that the only strains discussed in this review are either those identified as CC398 by MLST or CC398-associated types identified by spa typing. In the latter case, it is likely that the list of CC398associated spa types is not comprehensive and that additional rare types are likely present in the population, which have not been identified. Furthermore, there are additional MLSTs related to CC398, which are discussed elsewhere [56, 121] and are not thoroughly covered here.

The situation in North America regarding S.aureus in livestock appears to be different in substantial ways as compared with that characterized in Europe to date. For example, the diversity of S.aureus types found in pigs seems to be higher in North America than in Europe. A number of spa types unrelated to $\mathrm{CC} 398$ have been found in Canadian and US swine, including t002/ST5 [16, 94, 95, 4], t008/ST8 [123, 124], and t337/ST9 [122]. These types have also been found in raw meat products [125-127] in addition to CC398associated spa types. This diversity enormously complicates any surveillance efforts or attempts to determine a livestock origin versus a human origin of strains that may colonize a number of different species. Additionally, two papers have suggested that proximity to livestock farms or areas where manure is applied may increase the risk of acquiring MRSA colonization or developing an infection [128, 129], suggesting that other environmental factors in addition to direct contact with livestock may play a role in the development of S. aureus colonization and infections. And while potential markers for human versus livestock-associated CC398 strains have been suggested $[37,113]$, these need to be validated on a larger scale, as well as being tested to examine whether these or similar tests can differentiate livestock-associated or humanorigin isolates from other sequence types that may be zoonotic. Until such tests are identified and rigorously validated, the epidemiology of livestock-associated S.aureus in North America will remain muddled.

Finally, antibiotic use has been suggested to contribute to the evolution and spread of CC398 within the farming environment. This is due in large part to the findings that most livestock-associated CC398 isolates are resistant to antibiotics commonly used in agriculture, particularly beta lactams, tetracyclines, and macrolides. However, not all CC398 isolates are resistant to these drugs, with human-origin strains being more likely to be methicillin and tetracycline susceptible. Furthermore, resistance to zinc and other metals, which also may be present in animal feeds, could play a role in selection for antibiotic-resistant strains [130-132]. Additional research in this area is needed in order to determine the relative contributions of antibiotics, feed additives, and other practices on the farm and in the community to the evolution and spread of livestock-associated CC398 isolates.

\section{Compliance with Ethics Guidelines}

Conflict of Interest Tara C. Smith and Shylo E. Wardyn declare that they have no conflict of interest.

Human and Animal Rights and Informed Consent This article does not contain any studies with human or animal subjects performed by any of the authors.

\section{References}

Papers of particular interest, published recently, have been highlighted as:

- Of importance

1. Price J, Gordon NC, Crook D, Llewelyn M, Paul J. The usefulness of whole genome sequencing in the management of Staphylococcus aureus infections. Clin Microbiol Infect. 2013;19(9):784-9. doi:10.1111/1469-0691.12109.

2. Kock R, Becker K, Cookson B, van Gemert-Pijnen JE, Harbarth $\mathrm{S}$, Kluytmans J, et al. Systematic literature analysis and review of targeted preventive measures to limit healthcare-associated infections by meticillin-resistant Staphylococcus aureus. Euro Surveill. 2014;19(29):20860.

3. Rocha LA, Marques Ribas R, da Costa Darini AL, Gontijo Filho PP. Relationship between nasal colonization and ventilatorassociated pneumonia and the role of the environment in transmission of Staphylococcus aureus in intensive care units. Am J Infect Control. 2013;41(12):1236-40. doi:10.1016/j.ajic.2013.04. 009.

4. Holland TL, Arnold C, Fowler Jr VG. Clinical management of Staphylococcus aureus bacteremia: a review. JAMA. 2014;312(13):1330-41. doi:10.1001/jama.2014.9743.

5. From the Centers for Disease Control and Prevention. Four pediatric deaths from community-acquired methicillin-resistant Staphylococcus aureus-Minnesota and North Dakota, 19971999. JAMA. 1999;282(12):1123-5. 
6. Lina G, Piemont Y, Godail-Gamot F, Bes M, Peter MO, Gauduchon V, et al. Involvement of Panton-Valentine leukocidin-producing Staphylococcus aureus in primary skin infections and pneumonia. Clin Infect Dis. 1999;29(5):1128-32.

7. Wulf M, Voss A. MRSA in livestock animals - an epidemic waiting to happen. Clin Microbiol Infect. 2008;14(6):519-21. doi:10.1111/j.1469-0691.2008.01970.x.

8. Smith TC, Pearson N. The emergence of Staphylococcus aureus ST398. Vector Borne Zoonotic Dis. 2011;11(4):327-39. doi:10. 1089/vbz.2010.0072.

9. Bens CC, Voss A, Klaassen CH. Presence of a novel DNA methylation enzyme in methicillin-resistant Staphylococcus aureus isolates associated with pig farming leads to uninterpretable results in standard pulsed-field gel electrophoresis analysis. J Clin Microbiol. 2006;44(5):1875-6. doi:10.1128/JCM. 44.5. 1875-1876.2006.

10. Monecke S, Kuhnert P, Hotzel H, Slickers P, Ehricht R. Microarray based study on virulence-associated genes and resistance determinants of Staphylococcus aureus isolates from cattle. Vet Microbiol. 2007;125(1-2):128-40. doi:10.1016/j.vetmic. 2007.05.016.

11. Stegger M, Lindsay JA, Sorum M, Gould KA, Skov R. Genetic diversity in CC398 methicillin-resistant Staphylococcus aureus isolates of different geographical origin. Clin Microbiol Infect. 2010;16:1017-9. doi:10.1111/j.1469-0691.2009.03003.x.

12. Varshney AK, Mediavilla JR, Robiou N, Guh A, Wang X, Gialanella P, et al. Diverse enterotoxin gene profiles among clonal complexes of Staphylococcus aureus isolates from the Bronx, New York. Appl Environ Microbiol. 2009;75(21):6839-49. doi: 10.1128/AEM. 00272-09.

13. Armand-Lefevre L, Ruimy R, Andremont A. Clonal comparison of Staphylococcus aureus isolates from healthy pig farmers, human controls, and pigs. Emerg Infect Dis. 2005;11(5):711-4.

14. Voss A, Loeffen F, Bakker J, Klaassen C, Wulf M. Methicillinresistant Staphylococcus aureus in pig farming. Emerg Infect Dis. 2005;11(12):1965-6.

15. Huijsdens XW, van Dijke BJ, Spalburg E, van Santen-Verheuvel MG, Heck ME, Pluister GN, et al. Community-acquired MRSA and pig-farming. Ann Clin Microbiol Antimicrob. 2006;5:26. doi: 10.1186/1476-0711-5-26.

16. Khanna T, Friendship R, Dewey C, Weese JS. Methicillin resistant Staphylococcus aureus colonization in pigs and pig farmers. Vet Microbiol. 2008;128(3-4):298-303. doi:10.1016/j.vetmic.2007. 10.006 .

17. Smith TC, Male MJ, Harper AL, Kroeger JS, Tinkler GP, Moritz ED, et al. Methicillin-resistant Staphylococcus aureus (MRSA) strain ST398 is present in midwestern US swine and swine workers. PLoS One. 2009;4(1):e4258. doi:10.1371/journal.pone. 0004258 .

18. Uhlemann AC, Porcella SF, Trivedi S, Sullivan SB, Hafer C, Kennedy AD et al. Identification of a highly transmissible animal-independent Staphylococcus aureus ST398 clone with distinct genomic and cell adhesion properties. MBio. 2012;3(2). doi:10.1128/mBio.00027-12.

19. Price LB, Stegger M, Hasman H, Aziz M, Larsen J, Andersen PS, et al. Staphylococcus aureus CC398: host adaptation and emergence of methicillin resistance in livestock. MBio. 2012;3(1):58 9. doi:10.1128/mBio.00305-11. This study investigates the evolution of CC398 around the world, tracing its origin in humans and suggesting a species jump to pigs and other livestock.

20. David MZ, Siegel J, Lowy FD, Zychowski D, Taylor A, Lee CJ, et al. Asymptomatic carriage of sequence type 398, spa type t571 methicillin-susceptible Staphylococcus aureus in an urban jail: a newly emerging, transmissible pathogenic strain. J Clin Microbiol. 2013;51(7):2443-7. doi:10.1128/JCM. 01057-13
21. Krziwanek K, Metz-Gercek S, Mittermayer H. Methicillinresistant Staphylococcus aureus ST398 from human patients, upper Austria. Emerg Infect Dis. 2009;15(5):766-9.

22. Grisold AJ, Zarfel G, Hoenigl M, Krziwanek K, Feierl G, Masoud $\mathrm{L}$, et al. Occurrence and genotyping using automated repetitivesequence-based PCR of methicillin-resistant Staphylococcus aureus ST398 in Southeast Austria. Diagn Microbiol Infect Dis. 2009. doi:10.1016/j.diagmicrobio.2009.09.006.

23. van Cleef BA, Monnet DL, Voss A, Krziwanek K, Allerberger F, Struelens M, et al. Livestock-associated methicillin-resistant Staphylococcus aureus in humans. Eur Emerg Infect Dis. 2011;17(3):502-5.

24. Luxner J, Zarfel G, Johler S, Feierl G, Leitner E, Hoenigl M, et al. Genetic characterization of Staphylococcus aureus isolates causing bloodstream infections in Austria. Diagn Microbiol Infect Dis. 2014;78(2):153-6. doi:10.1016/j.diagmicrobio.2013.10.010.

25. Van Hoecke H, Piette A, De Leenheer E, Lagasse N, Struelens M, Verschraegen G, et al. Destructive otomastoiditis by MRSA from porcine origin. Laryngoscope. 2009;119(1):137-40. doi:10.1002/ lary. 20030

26. Vandendriessche S, Kadlec K, Schwarz S, Denis O. Methicillinsusceptible Staphylococcus aureus ST398-t571 harbouring the macrolide-lincosamide-streptogramin B resistance gene erm(T) in Belgian hospitals. J Antimicrob Chemother. 2011;66(11): 2455-9. doi:10.1093/jac/dkr348.

27. Lewis HC, Molbak K, Reese C, Aarestrup FM, Selchau M, Sorum M, et al. Pigs as source of methicillin-resistant Staphylococcus aureus CC398 infections in humans. Denmark. Emerg Infect Dis. 2008;14(9):1383-9.

28. de Vries LE, Christensen H, Skov RL, Aarestrup FM, Agerso Y. Diversity of the tetracycline resistance gene tet $(\mathrm{M})$ and identification of Tn916- and Tn5801-like (Tn6014) transposons in Staphylococcus aureus from humans and animals. J Antimicrob Chemother. 2009;64(3):490-500. doi:10.1093/jac/dkp214.

29. Larsen AR, Stegger M, Bocher S, Sorum M, Monnet DL, Skov RL. Emergence and characterization of community-associated methicillin-resistant Staphyloccocus aureus infections in Denmark, 1999 to 2006. J Clin Microbiol. 2009;47(1):73-8. doi: 10.1128/JCM. 01557-08.

30. Hartmeyer GN, Gahrn-Hansen B, Skov RL, Kolmos HJ. Pigassociated methicillin-resistant Staphylococcus aureus: family transmission and severe pneumonia in a newborn. Scand J Infect Dis. 2010;42(4):318-20. doi:10.3109/00365540903510708.

31. Omland O, Hoffmann L. Occupational acquisition of methicillinresistant Staphylococcus aureus in humans - a description of MRSA carrier and infected cases from the region of North Jutland in Denmark. Ann Agric Environ Med. 2012;19(4):63740.

32. Salmenlinna S, Lyytikainen O, Vainio A, Myllyniemi AL, Raulo S, Kanerva M, et al. Human cases of methicillin-resistant Staphylococcus aureus CC398. Finland. Emerg Infect Dis. 2010;16(10):1626-9. doi:10.3201/eid1610.091571.

33. Valentin-Domelier AS, Girard M, Bertrand X, Violette J, Francois P, Donnio PY, et al. Methicillin-susceptible ST398 Staphylococcus aureus responsible for bloodstream infections: an emerging human-adapted subclone? PLoS One. 2011;6(12):e28369. doi: 10.1371/journal.pone.0028369.

34. van der Mee-Marquet N, Francois P, Domelier-Valentin AS, Coulomb F, Decreux C, Hombrock-Allet C, et al. Emergence of unusual bloodstream infections associated with pig-borne-like Staphylococcus aureus ST398 in France. Clin Infect Dis. 2011;52(1):152-3. doi:10.1093/cid/ciq053.

35. Rasigade JP, Laurent F, Hubert P, Vandenesch F, Etienne J. Lethal necrotizing pneumonia caused by an ST398 Staphylococcus aureus strain. Emerg Infect Dis. 2010;16(8):1330. doi:10.3201/ eid1608.100317. 
36. Corvaglia AR, Francois P, Bertrand X, Quentin R, Hernandez D, van der Mee-Marquet N. Whole-genome sequences of two Staphylococcus aureus ST398 strains of human origin, S94 and S100. Genome Announc. 2013;1(5):e00691-13-13. doi:10.1128/ genomeA.00691-13. Additional genomic characterization of ST398 strains.

37. Chroboczek T, Boisset S, Rasigade JP, Tristan A, Bes M, Meugnier H, et al. Clonal complex 398 methicillin susceptible Staphylococcus aureus: a frequent unspecialized human pathogen with specific phenotypic and genotypic characteristics. PLoS One. 2013;8(11):e68462. doi:10.1371/journal.pone.0068462.

38. Tristan A, Rasigade JP, Ruizendaal E, Laurent F, Bes M, Meugnier $\mathrm{H}$, et al. Rise of CC398 lineage of Staphylococcus aureus among infective endocarditis isolates revealed by two consecutive population-based studies in France. PLoS One. 2012;7(12): e51172. doi:10.1371/journal.pone.0051172.

39. Senneville E, Briere M, Neut C, Messad N, Lina G, Richard JL, et al. First report of the predominance of clonal complex 398 Staphylococcus aureus strains in osteomyelitis complicating diabetic foot ulcers: a national French study. Clin Microbiol Infect. 2014;20(4):O274-7. doi:10.1111/1469-0691.12375.

40. Witte W, Strommenger B, Stanek C, Cuny C. Methicillin-resistant Staphylococcus aureus ST398 in humans and animals. Central Europe. Emerg Infect Dis. 2007;13(2):255-8.

41. Kock R, Brakensiek L, Mellmann A, Kipp F, Henderikx M, Harmsen D, et al. Cross-border comparison of the admission prevalence and clonal structure of meticillin-resistant Staphylococcus aureus. J Hosp Infect. 2009;71(4):320-6. doi: 10.1016/j.jhin.2008.12.001.

42. Kock R, Harlizius J, Bressan N, Laerberg R, Wieler LH, Witte W, et al. Prevalence and molecular characteristics of methicillinresistant Staphylococcus aureus (MRSA) among pigs on German farms and import of livestock-related MRSA into hospitals. Eur J Clin Microbiol Infect Dis. 2009;28(11):1375-82. doi: 10.1007/s10096-009-0795-4.

43. Kock R, Schaumburg F, Mellmann A, Koksal M, Jurke A, Becker $\mathrm{K}$, et al. Livestock-associated methicillin-resistant Staphylococcus aureus (MRSA) as causes of human infection and colonization in Germany. PLoS One. 2013;8(2):e55040. doi:10.1371/journal. pone.0055040.

44. Kock R, Siam K, Al-Malat S, Christmann J, Schaumburg F, Becker K, et al. Characteristics of hospital patients colonized with livestock-associated meticillin-resistant Staphylococcus aureus (MRSA) CC398 versus other MRSA clones. J Hosp Infect. 2011;79(4):292-6. doi:10.1016/j.jhin.2011.08.011.

45. Drougka E, Foka A, Marangos MN, Liakopoulos A, Makatsoris T, Anastassiou ED, et al. The first case of Staphylococcus aureus ST398 causing bacteremia in an immunocompromised patient in Greece. Indian J Med Microbiol. 2012;30(2):232-6. doi:10.4103/ 0255-0857.96706.

46. Pan A, Battisti A, Zoncada A, Bernieri F, Boldini M, Franco A, et al. Community-acquired methicillin-resistant Staphylococcus aureus ST398 infection. Italy. Emerg Infect Dis. 2009;15(5): $845-7$.

47. Mammina C, Cala C, Plano MR, Bonura C, Vella A, Monastero R, et al. Ventilator-associated pneumonia and MRSA ST398. Italy. Emerg Infect Dis. 2010;16(4):730-1.

48. Soavi L, Stellini R, Signorini L, Antonini B, Pedroni P, Zanetti L, et al. Methicillin-resistant Staphylococcus aureus ST398. Italy. Emerg Infect Dis. 2010;16(2):346-8.

49. Mammina C, Bonura C, di Carlo P, Cala C, Aleo A, Monastero R, et al. Daptomycin non-susceptible, vancomycin intermediate methicillin-resistant Staphylococcus aureus ST398 from a chronic leg ulcer. Italy. Scand J Infect Dis. 2010;42(11-12):955-7. doi:10. 3109/00365548.2010.524662.
50. Mammina C, Cala C, Bonura C, Di Carlo P, Aleo A, Fasciana T, et al. Polyclonal non multiresistant methicillin resistant Staphylococcus aureus isolates from clinical cases of infection occurring in Palermo, Italy, during a one-year surveillance period. Ann Clin Microbiol Antimicrob. 2012;11:17. doi:10.1186/14760711-11-17.

51. Monaco M, Pedroni P, Sanchini A, Bonomini A, Indelicato A, Pantosti A. Livestock-associated methicillin-resistant Staphylococcus aureus responsible for human colonization and infection in an area of Italy with high density of pig farming. BMC Infect Dis. 2013;13:258. doi:10.1186/1471-2334-13-258.

52. van Loo I, Huijsdens X, Tiemersma E, de Neeling A, van de Sande-Bruinsma N, Beaujean D, et al. Emergence of methicillinresistant Staphylococcus aureus of animal origin in humans. Emerg Infect Dis. 2007;13:1834-9.

53. van Rijen MM, Van Keulen PH, Kluytmans JA. Increase in a Dutch hospital of methicillin-resistant Staphylococcus aureus related to animal farming. Clin Infect Dis. 2008;46(2):261-3. doi: $10.1086 / 524672$.

54. Deurenberg RH, Nulens E, Valvatne H, Sebastian S, Driessen C, Craeghs J, et al. Cross-border dissemination of methicillinresistant Staphylococcus aureus. Euregio Meuse-Rhin region. Emerg Infect Dis. 2009;15(5):727-34.

55. Donker GA, Deurenberg RH, Driessen C, Sebastian S, Nys S, Stobberingh EE. The population structure of Staphylococcus aureus among general practice patients from the Netherlands. Clin Microbiol Infect. 2009;15(2):137-43. doi:10.1111/j.14690691.2008.02662.x.

56. Huijsdens XW, Bosch T, van Santen-Verheuvel MG, Spalburg E, Pluister GN, van Luit M, et al. Molecular characterisation of PFGE non-typable methicillin-resistant Staphylococcus aureus in the Netherlands, 2007. Euro Surveill. 2009;14(38):19335.

57. Rijnders MI, Deurenberg RH, Boumans ML, HoogkampKorstanje JA, Beisser PS, Stobberingh EE. The population structure of Staphylococcus aureus isolated from intensive care unit patients in the Netherlands over an eleven-year period (19962006). J Clin Microbiol. 2009;47(12):4090-5. doi:10.1128/JCM. 00820-09.

58. van Rijen MM, Bosch T, Heck ME, Kluytmans JA. Meticillinresistant Staphylococcus aureus epidemiology and transmission in a Dutch hospital. J Hosp Infect. 2009;72(4):299-306. doi:10. 1016/j.jhin.2009.05.006.

59. Wulf MW, Markestein A, van der Linden FT, Voss A, Klaassen C, Verduin CM. First outbreak of methicillin-resistant Staphylococcus aureus ST398 in a Dutch hospital. Euro Surveill. 2008;13(9):8051.

60. Wulf MW, Verduin CM, van Nes A, Huijsdens X, Voss A. Infection and colonization with methicillin resistant Staphylococcus aureus ST398 versus other MRSA in an area with a high density of pig farms. Eur J Clin Microbiol Infect Dis. 2012;31(1):61-5. doi:10.1007/s10096-011-1269-z.

61. van Duijkeren E, Ten Horn L, Wagenaar JA, de Bruijn M, Laarhoven L, Verstappen K, et al. Suspected horse-to-human transmission of MRSA ST398. Emerg Infect Dis. 2011;17(6): 1137-9. doi:10.3201/eid/1706.101330.

62. van Belkum A, Melles DC, Peeters JK, van Leeuwen WB, van Duijkeren E, Huijsdens XW, et al. Methicillin-resistant and susceptible Staphylococcus aureus sequence type 398 in pigs and humans. Emerg Infect Dis. 2008;14(3):479-83.

63. Verkade E, Bergmans AM, Budding AE, van Belkum A, Savelkoul P, Buiting AG, et al. Recent emergence of Staphylococcus aureus clonal complex 398 in human blood cultures. PLoS One. 2012;7(10):e41855. doi:10.1371/journal.pone. 0041855.

64. Fossum Moen AE, Saltyte Benth J, Alm-Kristiansen K, Bukholm G. Exotoxin-encoding gene content in community-acquired and 
hospital-acquired methicillin-resistant Staphylococcus aureus. Clin Microbiol Infect. 2009;15(12):1139-45. doi:10.1111/j.14690691.2009.02745.x.

65. Vindel A, Cuevas O, Cercenado E, Marcos C, Bautista V, Castellares C, et al. Methicillin-resistant Staphylococcus aureus in Spain: molecular epidemiology and utility of different typing methods. J Clin Microbiol. 2009;47(6):1620-7. doi:10.1128/ JCM. 01579-08.

66. Aspiroz C, Lozano C, Vindel A, Lasarte JJ, Zarazaga M, Torres C. Skin lesion caused by ST398 and ST1 MRSA, Spain. Emerg Infect Dis. 2010;16(1):157-9.

67. Lozano C, Rezusta A, Gomez P, Gomez-Sanz E, Baez N, MartinSaco G, et al. High prevalence of spa types associated with the clonal lineage CC398 among tetracycline-resistant methicillinresistant Staphylococcus aureus strains in a Spanish hospital. J Antimicrob Chemother. 2012;67(2):330-4. doi:10.1093/jac/ dkr497.

68. Lozano C, Aspiroz C, Ara M, Gomez-Sanz E, Zarazaga M, Torres C. Methicillin-resistant Staphylococcus aureus (MRSA) ST398 in a farmer with skin lesions and in pigs of his farm: clonal relationship and detection of $\ln u(\mathrm{~A})$ gene. Clin Microbiol Infect. 2011;17(6):923-7. doi:10.1111/j.1469-0691.2010.03437.x.

69. Lozano C, Aspiroz C, Charlez L, Gomez-Sanz E, Toledo M, Zarazaga $\mathrm{M}$, et al. Skin lesion by methicillin-resistant Staphylococcus aureus ST398-t1451 in a Spanish pig farmer: possible transmission from animals to humans. Vector Borne Zoonotic Dis. 2011;11(6):605-7. doi:10.1089/vbz.2010.0226.

70. Potel C, Alvarez-Fernandez M, Constenla L, Alvarez P, Perez S. First human isolates of methicillin-resistant Staphylococcus aureus sequence type 398 in Spain. Eur J Clin Microbiol Infect Dis. 2010;29(3):351-2. doi:10.1007/s10096-009-0860-z.

71. Camoez M, Sierra JM, Pujol M, Hornero A, Martin R, Dominguez MA. Prevalence and molecular characterization of methicillinresistant Staphylococcus aureus ST398 resistant to tetracycline at a Spanish hospital over 12 years. PLoS One. 2013;8(9):e72828. doi:10.1371/journal.pone.0072828.

72. Welinder-Olsson C, Floren-Johansson K, Larsson L, Oberg S, Karlsson L, Ahren C. Infection with Panton-Valentine leukocidin-positive methicillin-resistant Staphylococcus aureus t034. Emerg Infect Dis. 2008;14(8):1271-2.

73. Edwards G, Cosgrove B, Girvan K. ST398 MRSA infections in Scotland - no pig association apparent. International Symposium on Staphylococci and Staphylococcal Infections; Cairns, Australia; 2008.

74. Golding GR, Bryden L, Levett PN, McDonald RR, Wong A, Wylie J, et al. Livestock-associated methicillin-resistant Staphylococcus aureus sequence type 398 in humans, Canada. Emerg Infect Dis. 2010;16(4):587-94.

75. Yu F, Chen Z, Liu C, Zhang X, Lin X, Chi S, et al. Prevalence of Staphylococcus aureus carrying Panton-Valentine leukocidin genes among isolates from hospitalised patients in China. Clin Microbiol Infect. 2008;14(4):381-4. doi:10.1111/j.1469-0691. 2007.01927.x.

76. Chen H, Liu Y, Jiang X, Chen M, Wang H. Rapid change of methicillin-resistant Staphylococcus aureus clones in a tertiary care hospital of China over a 15-year period. Antimicrob Agents Chemother. 2010;54(5):1842-7. doi:10.1128/AAC. 01563-09.

77. Wu D, Wang Q, Yang Y, Geng W, Yu S, Yao K, et al. Epidemiology and molecular characteristics of communityassociated methicillin-resistant and methicillin-susceptible Staphylococcus aureus from skin/soft tissue infections in a children's hospital in Beijing. China. Diagn Microbiol Infect Dis. 2010;67(1):1-8. doi:10.1016/j.diagmicrobio.2009.12.006.

78. Wu D, Li X, Yang Y, Zheng Y, Wang C, Deng L, et al. Superantigen gene profiles and presence of exfoliative toxin genes in community-acquired meticillin-resistant Staphylococcus aureus isolated from Chinese children. J Med Microbiol. 2011;60(Pt 1):35-45. doi:10.1099/jmm. 0.023465-0.

79. Yao D, Yu FY, Qin ZQ, Chen C, He SS, Chen ZQ, et al. Molecular characterization of Staphylococcus aureus isolates causing skin and soft tissue infections (SSTIs). BMC Infect Dis. 2010;10:133. doi:10.1186/1471-2334-10-133.

80. Zhao C, Liu Y, Zhao M, Liu Y, Yu Y, Chen H, et al. Characterization of community acquired Staphylococcus aureus associated with skin and soft tissue infection in Beijing: high prevalence of PVL+ ST398. PLoS One. 2012;7(6):e38577. doi: 10.1371/journal.pone.0038577.

81. Jimenez JN, Velez LA, Mediavilla JR, Ocampo AM, Vanegas JM, Rodriguez EA, et al. Livestock-associated methicillin-susceptible Staphylococcus aureus ST398 infection in woman. Colombia. Emerg Infecti Dis. 2011;17(10):1970-1. doi:10.3201/eid1710. 110638.

82. Bhat M, Dumortier C, Taylor BS, Miller M, Vasquez G, Yunen J, et al. Staphylococcus aureus ST398, New York City and Dominican Republic. Emerg Infect Dis. 2009;15(2):285-7.

83. Uhlemann AC, Dumortier C, Hafer C, Taylor BS, Sanchez J, Rodriguez-Taveras C, et al. Molecular characterization of Staphylococcus aureus from outpatients in the Caribbean reveals the presence of pandemic clones. Eur J Clin Microbiol Infect Dis. 2012;31(4):505-11. doi:10.1007/s10096-011-1339-2.

84. Ip M, Yung RW, Ng TK, Luk WK, Tse C, Hung P, et al. Contemporary methicillin-resistant Staphylococcus aureus clones in Hong Kong. J Clin Microbiol. 2005;43(10):5069-73. doi:10. 1128/JCM. 43.10.5069-5073.2005.

85. Ho PL, Chuang SK, Choi YF, Lee RA, Lit AC, Ng TK, et al. Community-associated methicillin-resistant and methicillinsensitive Staphylococcus aureus: skin and soft tissue infections in Hong Kong. Diagn Microbiol Infect Dis. 2008;61(3):245-50. doi:10.1016/j.diagmicrobio.2007.12.015.

86. Mediavilla JR, Chen L, Uhlemann AC, Hanson BM, Rosenthal M, Stanak K, et al. Methicillin-susceptible Staphylococcus aureus ST398, New York and New Jersey USA. Emerg Infect Dis. 2012;18(4):700-2. doi:10.3201/eid1804.111419.

87. Orscheln RC, Hunstad DA, Fritz SA, Loughman JA, Mitchell K, Storch EK, et al. Contribution of genetically restricted, methicillinsusceptible strains to the ongoing epidemic of communityacquired Staphylococcus aureus infections. Clin Infect Dis. 2009;49(4):536-42. doi:10.1086/600881.

88. Uhlemann AC, Hafer C, Miko BA, Sowash MG, Sullivan SB, Shu Q, et al. Emergence of sequence type 398 as a community- and healthcare-associated methicillin-susceptible Staphylococcus aureus in northern Manhattan. Clin Infect Dis. 2013;57(5):700 3. doi:10.1093/cid/cit375.

89. Cui $\mathrm{S}, \mathrm{Li} \mathrm{J}, \mathrm{Hu} \mathrm{C}$, Jin $\mathrm{S}, \mathrm{Li} \mathrm{F}$, Guo Y, et al. Isolation and characterization of methicillin-resistant Staphylococcus aureus from swine and workers in China. J Antimicrob Chemother. 2009;64(4):680-3. doi:10.1093/jac/dkp275.

90. Wagenaar JA, Yue H, Pritchard J, Broekhuizen-Stins M, Huijsdens $\mathrm{X}$, Mevius DJ, et al. Unexpected sequence types in livestock associated methicillin-resistant Staphylococcus aureus (MRSA): MRSA ST9 and a single locus variant of ST9 in pig farming in China. Vet Microbiol. 2009;139(3-4):405-9. doi:10.1016/j.vetmic. 2009.06.014

91. Guardabassi L, O’Donoghue M, Moodley A, Ho J, Boost M. Novel lineage of methicillin-resistant Staphylococcus aureus. Hong Kong. Emerg Infect Dis. 2009;15(12):1998-2000. doi:10. 3201/eid1512.090378.

92. Yan X, Yu X, Tao X, Zhang J, Zhang B, Dong R, et al. Staphylococcus aureus ST398 from slaughter pigs in northeast China. Int J Med Microbiol. 2014;304(3-4):379-83. doi:10.1016/ j.ijmm.2013.12.003. 
93. Davies PR, Wagstrom EA, Bender JB. Lethal necrotizing pneumonia caused by an ST398 Staphylococcus aureus strain. Emerg Infect Dis. 2011;17(6):1152-3. doi:10.3201/eid/1706.101394. author reply 1153.

94. Smith TC, Gebreyes WA, Abley MJ, Harper AL, Forshey BM, Male MJ, et al. Methicillin-resistant Staphylococcus aureus in pigs and farm workers on conventional and antibiotic-free swine farms in the USA. PLoS One. 2013;8(5):e63704. doi:10.1371/journal. pone. 0063704 .

95. Frana TS, Beahm AR, Hanson BM, Kinyon JM, Layman LL, Karriker LA, et al. Isolation and characterization of methicillinresistant Staphylococcus aureus from pork farms and visiting veterinary students. PLoS One. 2013;8(1):e53738. doi:10.1371/ journal.pone.0053738.

96. Rinsky JL, Nadimpalli M, Wing S, Hall D, Baron D, Price LB, et al. Livestock-associated methicillin and multidrug resistant Staphylococcus aureus is present among industrial, not antibiotic-free livestock operation workers in North Carolina. PLoS One. 2013;8(7):e67641. doi:10.1371/journal.pone. 0067641.

97. Neyra RC, Frisancho JA, Rinsky JL, Resnick C, Carroll KC, Rule $\mathrm{AM}$, et al. Multidrug-resistant and methicillin-resistant Staphylococcus aureus (MRSA) in hog slaughter and processing plant workers and their community in North Carolina (USA). Environ Health Perspect. 2014;122(5):471-7. doi:10.1289/ehp. 1306741.

98. Leedom Larson KR, Smith TC, Donham KJ. Self-reported methicillin-resistant Staphylococcus aureus infection in USA pork producers. Ann Agric Environ Med. 2010;17(2):331-4.

99. Fanoy E, Helmhout LC, van der Vaart WL, Weijdema K, van Santen-Verheuvel MG, Thijsen SF, et al. An outbreak of nontypeable MRSA within a residential care facility. Euro Surveill. 2009;14((1):19080.

100. Grisold AJ, Zarfel G, Stoeger A, Feierl G, Raggam RB, Marth E. Emergence of community-associated methicillin-resistant Staphylococcus aureus (CA-MRSA) in Southeast Austria. J Infect. 2009;58(2):168-70. doi:10.1016/j.jinf.2008.12.004.

101. Declercq P, Petre D, Gordts B, Voss A. Complicated communityacquired soft tissue infection by MRSA from porcine origin. Infection. 2008;36(6):590-2. doi:10.1007/s15010-007-7029-4.

102. Denis O, Suetens C, Hallin M, Catry B, Ramboer I, Dispas M, et al. Methicillin-resistant Staphylococcus aureus ST398 in swine farm personnel Belgium. Emerg Infect Dis. 2009;15(7):1098-101.

103. Schijffelen M, Boel C, van Strijp J, Fluit A. Whole genome analysis reveals substantial diversification between pigassociated methicillin-resistant Staphylococcus aureus ST398 isolates. International Symposium on Staphylococci and Staphylococcal Infections; Cairns, Australia; 2008.

104. Cuny C, Nathaus R, Layer F, Strommenger B, Altmann D, Witte W. Nasal colonization of humans with methicillin-resistant Staphylococcus aureus (MRSA) CC398 with and without exposure to pigs. PLoS One. 2009;4(8):e6800. doi:10.1371/journal. pone. 0006800 .

105. Grundmann H, Aanensen DM, van den Wijngaard CC, Spratt BG, Harmsen D, Friedrich AW. Geographic distribution of Staphylococcus aureus causing invasive infections in Europe: a molecular-epidemiological analysis. PLoS Med. 2010;7(1): e1000215. doi:10.1371/journal.pmed.1000215.

106. Lipsky BA, Tabak YP, Johannes RS, Vo L, Hyde L, Weigelt JA. Skin and soft tissue infections in hospitalised patients with diabetes: culture isolates and risk factors associated with mortality, length of stay and cost. Diabetologia. 2010;53(5):914-23. doi: 10.1007/s00125-010-1672-5.

107. Klevens RM, Edwards JR, Tenover FC, McDonald LC, Horan T, Gaynes R. Changes in the epidemiology of methicillin-resistant Staphylococcus aureus in intensive care units in US hospitals,
1992-2003. Clin Infect Dis. 2006;42(3):389-91. doi:10.1086/ 499367.

108. European Food Safety Authority. Analysis of the baseline survey on the prevalence of methicillin-resistant Staphylococcus aureus (MRSA) in holdings with breeding pigs, in the EU, 2008 Part A: MRSA prevalence estimates. EFSA J. 2009;7(11):1376. doi:10. 2903/j.efsa.2009.1376.

109. Nemati M, Hermans K, Lipinska U, Denis O, Deplano A, Struelens M, et al. Antimicrobial resistance of old and recent Staphylococcus aureus isolates from poultry: first detection of livestock-associated methicillin-resistant strain ST398. Antimicrob Agents Chemother. 2008;52(10):3817-9. doi:10. 1128/AAC. 00613-08.

110. Mulders MN, Haenen AP, Geenen PL, Vesseur PC, Poldervaart ES, Bosch T, et al. Prevalence of livestock-associated MRSA in broiler flocks and risk factors for slaughterhouse personnel in the Netherlands. Epidemiol Infect. 2010;138(5):743-55. doi:10.1017/ S0950268810000075.

111. Lowder BV, Guinane CM, Ben Zakour NL, Weinert LA, ConwayMorris A, Cartwright RA, et al. Recent human-to-poultry host jump, adaptation, and pandemic spread of Staphylococcus aureus. Proc Natl Acad Sci U S A. 2009;106(46):19545-50. doi:10.1073/ pnas.0909285106.

112. Schmidt T, Zundorf J, Gruger T, Brandenburg K, Reiners AL, Zinserling J, et al. Phenotyping of Staphylococcus aureus reveals a new virulent ST398 lineage. Clin Microbiol Infect. 2013;19(3): 279-85. doi:10.1111/j.1469-0691.2012.03775.x.

113. Stegger M, Liu CM, Larsen J, Soldanova K, Aziz M, ContenteCuomo T, et al. Rapid differentiation between livestock-associated and livestock-independent Staphylococcus aureus CC398 clades. PLoS One. 2013;8(11):e79645. doi:10.1371/journal.pone. 0079645 .

114. Bootsma MC, Wassenberg MW, Trapman P, Bonten MJ. The nosocomial transmission rate of animal-associated ST398 meticillin-resistant Staphylococcus aureus. J R Soc Interface. 2011;8(57):578-84. doi:10.1098/rsif.2010.0349.

115. Wassenberg MW, Bootsma MC, Troelstra A, Kluytmans JA, Bonten MJ. Transmissibility of livestock-associated methicillinresistant Staphylococcus aureus (ST398) in Dutch hospitals. Clin Microbiol Infect. 2011;17(2):316-9. doi:10.1111/j.1469-0691. 2010.03260.x.

116. Hetem DJ, Bootsma MC, Troelstra A, Bonten MJ. Transmissibility of livestock-associated methicillin-resistant Staphylococcus aureus. Emerg Infect Dis. 2013;19(11):1797-802. doi:10.3201/eid1911. 121085.

117. van Cleef BA, Graveland H, Haenen AP, van de Giessen AW, Heederik D, Wagenaar JA, et al. Persistence of livestockassociated methicillin-resistant Staphylococcus aureus in field workers after short-term occupational exposure to pigs and veal calves. J Clin Microbiol. 2011;49(3):1030-3. doi:10.1128/JCM. 00493-10.

118. Verkade E, van Benthem B, den Bergh MK, van Cleef B, van Rijen M, Bosch T, et al. Dynamics and determinants of Staphylococcus aureus carriage in livestock veterinarians: a prospective cohort study. Clin Infect Dis. 2013;57(2):e11-7. doi:10. 1093/cid/cit228.

119. Kock R, Loth B, Koksal M, Schulte-Wulwer J, Harlizius J, Friedrich AW. Persistence of nasal colonization with livestockassociated methicillin-resistant Staphylococcus aureus in pig farmers after holidays from pig exposure. Appl Environ Microbiol. 2012;78(11):4046-7. doi:10.1128/AEM. 00212-12.

120. Slingerland BC, Tavakol M, McCarthy AJ, Lindsay JA, Snijders SV, Wagenaar JA, et al. Survival of Staphylococcus aureus ST398 in the human nose after artificial inoculation. PLoS One. 2012;7(11):e48896. doi:10.1371/journal.pone.0048896. 
121. Stegger M, Aziz M, Chroboczek T, Price LB, Ronco T, Kiil K, et al. Genome analysis of Staphylococcus aureus ST291, a double locus variant of ST398, reveals a distinct genetic lineage. PLoS One. 2013;8(5):e63008. doi:10.1371/journal.pone.0063008.

122. Dressler AE, Scheibel RP, Wardyn S, Harper AL, Hanson BM, Kroeger JS, et al. Prevalence, antibiotic resistance and molecular characterisation of Staphylococcus aureus in pigs at agricultural fairs in the USA. Vet Rec. 2012;170(19):495. doi:10.1136/vr. 100570 .

123. Osadebe LU, Hanson B, Smith TC, Heimer R. Prevalence and characteristics of Staphylococcus aureus in Connecticut swine and swine farmers. Zoonoses Public Health. 2013;60(3):234 43. doi: 10.1111/j.1863-2378.2012.01527.x.

124. Lin Y, Barker E, Kislow J, Kaldhone P, Stemper ME, Pantrangi M, et al. Evidence of multiple virulence subtypes in nosocomial and community-associated MRSA genotypes in companion animals from the upper midwestern and northeastern United States. Clin Med Res. 2011;9(1):7-16. doi:10.3121/cmr.2010.944.

125. Waters AE, Contente-Cuomo T, Buchhagen J, Liu CM, Watson L, Pearce K, et al. Multidrug-resistant Staphylococcus aureus in US meat and poultry. Clin Infect Dis. 2011;52(10):1227-30. doi:10. 1093/cid/cir181.

126. $\mathrm{Pu} \mathrm{S}, \mathrm{Han} \mathrm{F}, \mathrm{Ge} \mathrm{B}$. Isolation and characterization of methicillinresistant Staphylococcus aureus strains from Louisiana retail meats. Appl Environ Microbiol. 2009;75(1):265-7. doi:10.1128/ AEM. 01110-08.

127. Hanson BM, Dressler AE, Harper AL, Scheibel RP, Wardyn SE, Roberts LK, et al. Prevalence of Staphylococcus aureus and methicillin-resistant Staphylococcus aureus (MRSA) on retail meat in Iowa. J Infect Public Health. 2011;4(4):169-74. doi:10. 1016/j.jiph.2011.06.001.

128. Casey JA, Curriero FC, Cosgrove SE, Nachman KE, Schwartz BS. High-density livestock operations, crop field application of manure, and risk of community-associated methicillin-resistant Staphylococcus aureus infection in Pennsylvania. JAMA Intern Med. 2013;173(21):1980-90. doi:10.1001/jamainternmed.2013. 10408.

129. Carrel M, Schweizer ML, Sarrazin MV, Smith TC, Perencevich EN. Residential proximity to large numbers of swine in feeding operations is associated with increased risk of methicillin-resistant Staphylococcus aureus colonization at time of hospital admission in rural Iowa veterans. Infect Control Hosp Epidemiol. 2014;35(2):190-3. doi:10.1086/674860.

130. Aarestrup FM, Cavaco L, Hasman H. Decreased susceptibility to zinc chloride is associated with methicillin resistant Staphylococcus aureus CC398 in Danish swine. Vet Microbiol. 2010;142(3-4):455-7. doi:10.1016/j.vetmic.2009.10.021.

131. Cavaco LM, Hasman H, Aarestrup FM. Zinc resistance of Staphylococcus aureus of animal origin is strongly associated with methicillin resistance. Vet Microbiol. 2011;150(3-4):344-8. doi:10.1016/j.vetmic.2011.02.014.

132. Cavaco LM, Hasman H, Stegger M, Andersen PS, Skov R, Fluit $\mathrm{AC}$, et al. Cloning and occurrence of $c z r \mathrm{C}$, a gene conferring cadmium and zinc resistance in methicillin-resistant Staphylococcus aureus CC398 isolates. Antimicrob Agents Chemother. 2010;54(9):3605-8. doi:10.1128/AAC. 00058-10.

133. Ruhlmann CH, Kolmos HJ, Kristiansen JE, Skov R. Pigs as an infection source for methicillin resistant Staphylococcus aureus infections in humans. Ugeskr Laeger. 2008;170(43):3436.

134. Rasigade JP, Laurent F, Lina G, Meugnier H, Bes M, Vandenesch F, et al. Global distribution and evolution of Panton-Valentine leukocidin-positive methicillin-susceptible Staphylococcus aureus, 1981-2007. J Infect Dis. 2010;201(10):1589-97. doi:10. 1086/652008.

135. van Wamel WJ, Hansenova Manaskova S, Fluit AC, Verbrugh H, de Neeling AJ, van Duijkeren E, et al. Short term micro-evolution and PCR-detection of methicillin-resistant and -susceptible Staphylococcus aureus sequence type 398. Eur J Clin Microbiol Infect Dis. 2010. doi:10.1007/s10096-009-0816-3.

136. Zhang K, McClure JA, Elsayed S, Louie T, Conly JM. Novel multiplex PCR assay for characterization and concomitant subtyping of staphylococcal cassette chromosome mec types I to V in methicillin-resistant Staphylococcus aureus. J Clin Microbiol. 2005;43(10):5026-33. doi:10.1128/JCM. 43.10.50265033.2005.

137. Jansen MD, Box AT, Fluit AC. SCCmec typing in methicillinresistant Staphylococcus aureus strains of animal origin. Emerg Infect Dis. 2009;15(1):136-7. author reply 137. 